\title{
Technical Efficiency of Maize Producer Smallholder Farmers in Alefa Woreda, North Western Ethiopia
}

\author{
Getahun Mitikie* \\ Women and Children Affairs Office, Alefa Woreda, Ethiopia \\ Yenetila Alamneh $(\mathrm{PhD})$ \\ Department of Agricultural Economics, Debre Markos University, Ethiopia \\ Derjew Fentie $(\mathrm{PhD})$ \\ Department of Agricultural Economics, Debre Markos University, Ethiopia
}

\begin{abstract}
Efficient uses of the existing resources by farm households improve their productivity and thereby increase their output. Maize is one of the dominant crops in the study area; however its productivity is very low. This shows that it is possible to raise output from existing inputs used if resources are properly used and efficiently allocated. The productivity of maize can be changed due to differences in the efficiency of the production process. Hence, this study aimed to analyzing the technical efficiency of maize production in Alefa District of central Gondar in Ethiopia. The objective of study was to measure the level of technical efficiency of maize producers and to identify the determinants of technical efficiencies in maize production among smallholder farmers in the study area. To address the objective of the study both primary and secondary data were collected. The primary data were collected from 152 maize producer farmers by two- stage sampling technique during 2019/20 production season. For data collection personal interview through a structural interview scheduled was employed. Both descriptive and inferential statistics were used for data analysis. Technical efficiency of sampled farmers in maize production was estimated and analyzed by Cobb-Douglas functional form in stochastic frontier model (SFM) with single stage estimation method. The estimated SFM indicated that input variables (land, labor, oxen and DAP) were found significantly and positively influence maize production. The production of maize by sampled farmers was characterized in constant return to scale (1.08). The estimated gamma $(\gamma)$ parameter was 0.91 , which measures the relative deviation of output from the frontier level due to inefficiency. This implies that about $91 \%$ of the total variation in maize output was due to technical inefficiency effects. The estimated mean level of TE of maize producers was 0.82 . This implies that production can be increased by 18 percent given the existing technological level. The results of this study indicated that among the farm specific, socioeconomic and institutional factors hypothesized to affect TE, age, family size, education status, frequency of extension contact, off farm income and credit access were significant determinants of the production level of maize. The findings obtained in this study could be quite useful to policy makers. Policy interventions should focus more on timely supply of DAP, and socioeconomic significant variables such as education, age, credit access, off farm income, family size and extension contact improve farmers' efficiency in production of maize.
\end{abstract}

Keywords/Phrase: Maize Production, Single Stage Estimation, Stochastic Frontier Model, Technical Efficiency DOI: $10.7176 / \mathrm{JAAS} / 68-05$

Publication date:September $30^{\text {th }} 2020$

\section{INTRODUCTION}

Agricultural is the main pillar of Ethiopian economy contributing about 41 percent to the GDP and 85 percent to national export earnings. It also supplies a proportion of the industrial raw materials while employing about 85 percent of the population MoFED (2015). Nearly all agricultural holders attain the food they consume and the money they require to cover every day expenditures from farming activities CSA (2016).

The agricultural sector is the country's main source of economic growth under Ethiopia's Growth Transformation Plan (GTP), with attention given to productivity and production increase which is crucial for the country's effort to attain food security and increase export earnings through effective and efficient mobilization and utilization of the scarce resources UNDP (2017).

The sources of growth have come from an increased area under cultivation and from increased productivity, agricultural modernization, development of new export sectors, strong global commodity demand and government-led development investments MoA (2015).

Maize was originated in America and it is the world's third most important food crop next to rice and wheat. It was introduced to Ethiopia during the late $16^{\text {th }}$ or early $17^{\text {th }}$ century. Since its introduction, it has gained much importance and at present stands first in total annual grain production and second in terms of area coverage among cereals in Ethiopia FAO (2014).

Ethiopia is one of the world's centers of genetic diversity in crop germplasm and produces more of maize 
than any other crops CSA, (2016).Maize is Ethiopia's staple cropand is widely grown in most part by small holder farmers through out the country. Maize production was 42 millionqt,40\%higher than teff and $75 \%$ higher than wheat production. With an average yield of 17.4qtperhect are (equalto 32 million qt grown over1.8 million hectares) from 2010 to 2013; maize has been the leading cerealcrop in Ethiopia since the mid-1990s in terms of both cropyield and production (Rashid et al., 2010).

Maize is a major crop in central Gondar areas of Amhara Region of Ethiopia. Farmers grow maize mainly to consumeits green cobasan additional meal. They also use it to make different traditional food items like corn flour, porridge, bread, cornmeal, for brewing beveragealcohol, livestock feed,cornoilandethanol production. Whereas, in major maize producing areas of central Gondar,maize grain is used to make almost all kinds of traditional dishes with or without mixing witho the rcrops. However, due to its scarcity, the utilization of green maizes talk was limited to feed cattle, particularly draught animals, dairy cows and physically weak animals.It is estimated that 20.72 tonperhect are of maizes talk can be produced (Geta et al., 2013). Despite the efforts directed at improving maize production over the years,low productivity remains major challenge in agricultural sub-sector.

Hence, the average national on farm level yields of 21qtperha compare sun favorably with on farm field trial yields of50-60qt/ha and on research field yield 80-110qt/ha(Dawitetal.,2010). As a result, efforts towards development of maize in central Gondar have been focused on development and dissemination of high yielding varieties to raise productivity of small holder farmers FAO (2011). This means technological advances generated through research fail to be translated into increasing efficiency and resource productivity(Geta et al., 2013).

Alefa District is endowed with favorable climatic and natural resource conditions that can grow diverse annual and perennial crops required for household consumption and for the market. Despite the fact that, the district produces agricultural products based on rain-fed. According to DARDO (2019), the major cereal crops grown in the district include maize, teff, finger millet, barley and bean.

Therefore, this study was intended to measure the technical efficiency of maize producer small holder farmers and identify its determinant factors in the Alefa District.

\section{RESEARCH METHODOLOGY}

Description of the Study Area

The study was conducted in Alefa District,central Gondar Zone, Amhara Region of Ethiopia. Alefa is located 649 $\mathrm{km}$ from north of the capital city of Addis Ababa and $88 \mathrm{~km}$ west of the capital city of Amhara National RegionalState, Bahir Dar and is far $142 \mathrm{~km}$ from central Gondar Administrative Zone. The district is also located about $649 \mathrm{~km}$ North of Addis Ababa at $11^{\circ 0} 40^{\prime} 24^{\prime \prime}-12^{0} 11^{\prime} 56^{\prime \prime} \mathrm{N}$ latitude and 360 31’31" - 370 7’39" E longitude. Alefa is bordered on the south by Awi Zone, on the west by Qwara, on the north by Takusa, on the east by Lake Tana.

\section{Data Type, Sources and Collection Methods}

In order to address the objectives of the study, both primary and secondary data were collected.

Primary data: The main sources of primary data were smallholder farmers randomly selected from different rural kebeles, farmers' service cooperative association (Union). The data were collected formally by individual interviewers using structured interview schedule questionnaire..

Secondary data: These data were collected by reviewing the relevant documents of nationally authenticated organizations such as Alefa District Office of Agriculture and Rural Development, Central Statistical Agency (CSA), Bureau of Agriculture and Rural Development, and international organizations (such as FAO).Besides relevant published and unpublished reports and bulletins were browsed to generate relevant secondary information focusing on technical efficiency on maize production.

\section{Sampling Techniques and Sample Size Determination}

A two-stage sampling procedure was used for the selection of sample household heads. Alefa District consists of 34 rural Kebele Administrations (KAs). In the first stage, out of the 34 rural kebeles 5 rural kebeles were selected randomly as all kebeles are producers of maize in the district. Then, the list of maize grower household heads of each rural kebele was identified in collaboration with experts of DARDO, kebele leaders, key informants and development agents of the respective rural kebeles.

In the second stage, based on a complete list of names of all maize producer smallholder farmers in each selected kebeles, sample of smallholder farmers from each selected rural kebele were selected using probability proportional sample size (PPS) technique.

\section{Methods of Data Analysis}

To address the objectives of the study, both descriptive and econometric methods were used. Means, standard deviations, percentages and frequencies were used in analyzing the socio-economic characteristics of the farmers, input and output variables and the distributions of efficiency levels.

A stochastic frontier production function that incorporated inefficiency factors was estimated using Maximum Likelihood Estimation (MLE) technique to obtain farm specific technical efficiencies as well as their determinants

A generalized likelihood ratio test was carried out to ascertain whether the farmers were fully technically 
efficient.

Specification of the econometric model

The SPF model in general production function for the $\mathrm{i}^{\text {th }}$ farmer's maize production is given by:

$Y_{i}=f(X i j: \beta)+\varepsilon_{i}$

Where:

$\mathrm{Y}_{\mathrm{i}}=$ output of the $\mathrm{i}^{\text {th }}$ farmer;

$\mathrm{X}_{\mathrm{ij}}=\mathrm{a}$ vector of actual input variables used by the $\mathrm{i}^{\text {th }}$ farmer

$\beta=$ a vector of production coefficients to be estimated;

$\varepsilon_{\mathrm{i}}=$ is a composed error term $\left(\mathrm{V}_{\mathrm{i}}-\mathrm{U}_{\mathrm{i}}\right)$

$\mathrm{V}_{\mathrm{i}}=$ Random variability in the production that cannot be influenced by the farmer;

$\mathrm{U}_{\mathrm{i}}=$ deviation from maximum potential output attributable to technical in/efficiency relative tothe stochastic frontier which is given by $f\left(X_{i j} ; \beta\right)+V_{i}$ and assumes only positive values.

Selection of the functional form

Following the Aigner et al. (1977) and Meeusen and Van den Broeck (1977) stochastic frontierproduction function was estimated with a Cobb-Douglas production functional type of specification. The Cobb-Douglas functional model was specified as follows to estimate the technical efficiency level in maize production of smallholder farmers in the study area.

$\ln \mathrm{Y}_{\mathrm{i}}=\ln \beta \mathrm{o}+\Sigma \beta \mathrm{j} \ln \mathrm{Xij}+\mathrm{V}_{\mathrm{i}}-\mathrm{U}_{\mathrm{i}}$ or

$\mathrm{LN}(O U T P) i=\beta 0 i+\beta 1 \ln (\mathrm{LAND}) i+\beta 2 \ln (L A B) i+\beta 3 \ln (\mathrm{SEED}) i+\beta 4 \ln (\mathrm{OXNP}) i+\beta 5 \ln (\mathrm{UREA}) i+\beta 6 \ln (\mathrm{DAP}) i$ $+v i-[\delta 0 i+\delta 1(A G E) i+\delta 2(E D U C L E V) i+\delta 3(\mathrm{SEX}$ of HH) $i+\delta 4(F A M S Z) i+\delta 5$ (FRAG OF LAND) $i+$ $\delta 6($ CREDITACECSE $) i+\delta 7$ (OWERSHIP OF LAND) $i+\delta 8$ (TLU) $i+\delta 9$ (OFFFARMINCOME) $i+\delta 10($ FREQOFEX. CONTACT) $i$

Where:

$\mathbf{L n}=$ The natural logarithm (i.e., to base e)

OUTP=Total output of maize produced by the $i^{\text {th }}$ sample household, measured in $\mathrm{qt}$

Land $=$ Size of area on which maize was grown by the sample household.

$\mathbf{L A B}=$ Amount of man-equivalent labor used in maize production $i^{\text {th }}$ the sample household

SEED $=$ is total amount of seeds sown in maize plot in kilogram

DAP $=$ is the quantity of DAP input applied by the $i^{\text {th }}$ farmer in kilogram

UREA $=$ is the quantity of urea input applied by the $i^{\text {th }}$ farmer in kilogram

$\mathbf{O X N P}=$ is oxen inputs used by the $\mathrm{i}^{\text {th }}$ farmer in pair of oxen-days

FAMSZ $=$ Size of family members including the household head living in the $i^{\text {th }}$ sample household head in years,

EDUC $=$ Schooling of the household head in years

LVSTCK=Number of livestock owned by the farmer and measured in TLU

SEX OF HH = It refers to the gender of household head

FRAG OF LAND = It refers to the fragmented of maize plots

CREDITACECSE $=$ Access to credit during maize production season

OWERSHIP OF LAND= It refers the land ownership by farmer during maize production.

OFF FARM INCOME=this refers to the participating of sampled household in different activities outside his/her farm in the production year.

FREQ OF EX. CONTACT $=$ this refers to the frequency of contacts with extension workers in a year and the linkage between farmers with development agents.

$\mathbf{V}_{\mathbf{i}}=$ is a symmetric error term accounting for the deviation from the frontier because of factors which are beyond the control of the farmer (such as variation in weather, measurement error and other statistical noise) and $\mathbf{u}_{\mathrm{i}}=$ is a one-sided error term accounting for the deviation because of efficiency effects.

\section{RESULTS AND DISCUSSION}

\section{Level of production and input utilization in maize production}

The sample smallholder farmers realized a mean yield of 26.18qt/ha(Table1). Sample Smallholder farmers were explained the productivity level achieved in the cropping season is lower than their average yield of the good season. Late time moisture stress and untimely Fertilizer supply was mentioned to be causes of yield loss for maize in the cropping season.

Assessing the productivity loss estimated by these and other similar externalities to have Policy relevance. To this end, smallholder farmers were asked how much they could have Obtained from their maize plots in the cropping season had there been no hazard or good Climatic condition to their maize cultivation. Furthermore, the two commonly used chemical fertilizers in the production of maize were DAP and Urea. The average amount of DAP and Urea applied by sample smallholder farmers were average $129.53 \mathrm{~kg}$ and $180.49 \mathrm{~kg}$ per ha, respectively. In general, there was high variation in the application of fertilizers in maize production among the sample 
smallholder farmers. The average amount of seed applied by sample smallholder farmers were $24.66 \mathrm{~kg}$ per ha.

Table1:Level of production and input application in maize production

\begin{tabular}{|l|l|l|l|l|}
\hline Item & Mean & Std. Deviation & Minimum & Maximum \\
\hline Output (Qt/ha) & 26.18 & 10.41 & 8 & 50 \\
\hline Maize land (ha) & 1.11 & 0.63 & 0.5 & 2 \\
\hline Labor (MD/ha) & 20.45 & 8.91 & 11 & 27.5 \\
\hline Seed (Kg/ha) & 24.66 & 6.06 & 12.5 & 45 \\
\hline Dap (Kg/ha) & 129.53 & 71.13 & 50 & 300 \\
\hline Urea (Kg/ha) & 180.49 & 80.35 & 70 & 380 \\
\hline Oxen (OD/ha) & 4.11 & 1.54 & 3 & 8 \\
\hline
\end{tabular}

Source:Computed from field survey data (2020)

The survey results revealed that on average, human labor days used in the cultivation of maize was 20.45 mandays per hectare with the standard deviation of 6.06 (Table 1). Similarly, the mean use of oxen day was 4.11 oxen days per ha with the standard deviation of 1.54 oxen days.

\section{Results of Econometric Analysis}

Parameter estimates of the SPF model

A single stage maximum likelihood estimation procedure was employed to estimate simultaneously the parameters of both stochastic frontier production function and efficiency effect model as presented.

Table 2: Maximum likelihood estimates of Cobb-Douglas SPF with determinants

\begin{tabular}{|c|c|c|c|c|c|}
\hline Input variables & parameters & Coefficient & Standard error & Z-value & P-value \\
\hline Constant & $\beta_{\mathrm{o}}$ & $2.0638 * * *$ & 0.1865 & 11.07 & 0.000 \\
\hline Lnland & $\beta_{1}$ & $0.1226 * * *$ & 0.0357 & 3.43 & 0.001 \\
\hline lnlabor & $\beta_{2}$ & $0.1794 * * *$ & 0.0450 & 3.98 & 0.000 \\
\hline lnseed & $\beta_{3}$ & 0.0160 & 0.0165 & 0.97 & 0.334 \\
\hline lnurea & $\beta_{4}$ & 0.0426 & 0.0481 & 0.89 & 0.375 \\
\hline $\ln \mathrm{DAP}$ & $\beta_{5}$ & $0.0916^{*}$ & 0.0468 & 1.95 & 0.050 \\
\hline Lnoxen & $\beta_{6}$ & $0.6367 * *$ & 0.3214 & 1.98 & 0.047 \\
\hline \multicolumn{6}{|c|}{ Determinant variables } \\
\hline Constant & $\delta_{0}$ & -3.9815 & 2.6875 & -1.50 & 0.138 \\
\hline Age & $\delta_{1}$ & $0.0770^{*}$ & 0.0406 & 1.89 & 0.058 \\
\hline Education & $\delta_{2}$ & -0.0672 & 0.4906 & -0.15 & 0.881 \\
\hline Family size & $\delta_{3}$ & $-0.3754 * *$ & 0.1900 & -1.98 & 0.047 \\
\hline Sex & $\delta_{4}$ & 0.5943 & 0.3827 & -1.66 & 0.119 \\
\hline Off farm income & $\delta_{5}$ & $1.4474 * * *$ & 0.4591 & 3.15 & 0.003 \\
\hline Credit access & $\delta_{6}$ & $-2.2434 * * *$ & 0.5646 & -3.97 & 0.000 \\
\hline Fragmented of plot & $\delta_{7}$ & -0.7071 & 0.5901 & -1.20 & 0.937 \\
\hline Livestock holding & $\delta_{8}$ & 0.0015 & 0.0459 & 0.04 & 0.937 \\
\hline Ownership of plot & $\delta_{9}$ & -0.0918 & 0.1038 & -0.78 & 0.376 \\
\hline Freq of ex. contact & $\delta_{10}$ & 0.0072 & 0.2104 & -0.03 & 0.972 \\
\hline
\end{tabular}

Variance parameters
\begin{tabular}{|l|l|l|l|l|l|}
\hline Sigma-squared & $\delta^{2}$ & 0.012 & 0.0021 & & \\
\hline Gamma & $\gamma$ & 0.91 & & & \\
\hline Lambda & $\lambda$ & 3.355 & 0.017 & & \\
\hline Mean of TE & & 0.82 & & & \\
\hline Returns to scale & & 1.06 & & & \\
\hline Log likelihood & LL & 117.7 & & & \\
\hline Total sample size & $\mathrm{N}$ & 152 & & & \\
\hline
\end{tabular}

Source: Computed from field survey data (2020)

$* * *, * * *$ implies significant at $1 \%, 5 \%$ and $10 \%$ probability levels, respectively.

The results of the Cobb-Douglas Stochastic Production Frontier showed that the estimated Coefficient for land, labor, DAP and oxen power were found to be positive. This positive sign confirms to a priori expectations. The estimated coefficient of land, labor, oxen and DAP power were found to be positively and significantly affect the level of technical efficiency of maize production at 1, 5 and 10 percent level of significant, respectively. The Coefficient of land, labor, DAP and oxen power variables are 0.1226, 0.1794, 0.0916 and 0.6377, respectively. Since, the increase in these inputs can be increase production of maize significantly and this implies that increasing the level of these inputs will shift the production function upward. This finding was line with the finding of (Abebayehu, 2011). However, the input urea and seed were found to be statistically insignificant. This implies that 
the amount of that input did not affect technical efficiency of maize production in the study area.

The estimated coefficient of seed and urea was found to be positive and insignificantly affect the level of technical efficiency of maize production. The coefficient of seed variable is 0.0160 with positive sign. This indicates that 1 percent increase in seed usage will increase the maize yield by 0.016 percent, but this coefficient is insignificant. The main reason for this farmeruses less seed rate below the recommended one. This finding was line with the finding of (Isaac, 2011). On the other hand, it contradicted the finding of (Beyan et al., 2013; Abdi et al., 2012).

\section{Determinants of technical inefficiency}

Of the selected variables in the model, family size and credit access produced negatively significant coefficients to the inefficiency model. In other words, the level of technical inefficiency decreases as family size and credit access increase (technical efficiency increases as family size and credit access increase).

The result is similar to the expectation that those households having large family size are less inefficient than households having small family size, because; family labor is the main input in crop production. As the households have large family size, he/she would manage crop plots on time and may be able to use appropriate input combinations. The result is consistent with the findings of Solomon (2014) and Akanbi et al.(2011).

The coefficient of credit recipient has consistent with the previous expected negative sign and statistically significant effect on technical inefficiency at $1 \%$ level of significance. This implies that access to credit is a significant factor in enhancing efficiency of maize producer smallholder farmers in the study area. These findings can be attributed to the fact that credit permits a sample smallholder farmer to enhance efficiency by overcoming liquidity constraints. Hence, use of credit access ensures timely acquisition and use of agricultural inputs such as improved seed, DAP, Urea, education and implement farm management decisions on time and these results increased production of efficiency.

On the other hand, the coefficients of age and off farm income are found to be positively significant at $10 \%$ and $1 \%$ level of significance, respectively. This suggested that younger farmers were more efficient than their old counterparts. Similarly, those households engaged in some off-farm activities are technically inefficient relative to those who were not engaged in activities other than their farm operations.

\section{Estimation of farmer level technical efficiency in maize production}

The estimation result shows that the mean level of technical efficiency of maizegrowing farmers was about $82 \%$, with their efficiency ranges from the most inefficient level of $29 \%$ which was far below from efficient frontier by 71 percent to the highest level of efficiency was 99 percent which was only 1 percent away from the frontier with 0.20 std deviation (Table 1).

This shows that there is a wide disparity among maizeproducer farmers in their level of technical efficiency which may in turn indicate that, there exists a room for improving the existing level of maizeproduction through enhancing the level of farmers, technical efficiency.

This variation in the technical efficiency of maize producers was probably due to differences in managerial decisions and farm characteristics that may affect the ability of the producer to adequately use the existing technology.

As result show farmers participated in maize production during 2019/20 in the study was not efficient and on average 18 percent of the maize output was lost due to inefficiency of producers.

This indicates that on average farmers can increase their current level of output by 18 percent without increasing additional inputs rather than using existing levels of inputs, or, the result shows those smallholder farmers on the average can decrease their current levels of inputs consumption by 18 percent without reducing currently level of output. Generally, the study result indicated that there is a room for improving the existing level of maize, production through enhancing the level of farmers' technical efficiency. 
Table 3: Technical efficiency score of individual households

\begin{tabular}{|l|l|l|}
\hline Efficiency category & No. of sample small holder farmers & Percent \\
\hline $0.29-0.40$ & 2 & 1.32 \\
\hline $0.41-0.50$ & 15 & 9.87 \\
\hline $0.51-0.60$ & 11 & 7.24 \\
\hline $0.61-0.70$ & 11 & 7.24 \\
\hline $0.71-0.80$ & 20 & 13.16 \\
\hline $0.81-0.90$ & 7 & 4.61 \\
\hline $0.91-0.99$ & 86 & 56.58 \\
\hline Total & $\mathbf{1 5 2}$ & $\mathbf{1 0 0}$ \\
\hline Mean & 0.82 & \\
\hline Maximum & 0.99 & \\
\hline Minimum & 0.29 & \\
\hline Std deviation & 0.20 & \\
\hline
\end{tabular}

Source: Computed from field survey data (2020)

Moreover, there is a considerable difference in technical efficiency among farmers that ranged from a minimum of 0.29 to a maximum of 0.99 .

\section{CONCLUSION}

The results of efficiency analysis showed that smallholder farmers could improve their efficiency by operating closer to production frontier. Thus, there existed considerable scope to expand output and also productivity by increasing the average yield gap between the most efficient and less efficient farm smallholder farmers.

This amount of output and efficiency in the utilization of production input could be obtained significantly by paying more attention to the determinants of technical efficiency.

\section{Policy implications and recommendations}

The positive and significance of major inputs such as land ( maize plot), DAP, labor, and oxen-days show the importance of conventional inputs in smallholder farmers implying better access and use of these inputs could lead to higher maize production and productivity in the study area. Enhancing the productivity of these factors of production is necessary. of maize

Policy interventions should focus more on timely supply of DAP to improve farmers' efficiency in production

The study has shown that access to credit improves technical efficiency. Credit is necessary to empower smallholder farmers to purchase inputs that they cannot afford from their own resources, which enhance production and productivity of maize.

It was shown that off farm income has a positive influence with technical efficiency and farmers are encourage to diversify their production by not only engaging in farm production but also in off farm income generating activities in order to earn more income that can be used to facilitate farm activities.

\section{REFERENCES}

Abebayehu, G. (2011). Technical efficiency analysis of haricot bean seed production, the case of Boricha District,Sidama Zone, Southern Ethiopia, In partial fulfillment of the requirements for the Degree of Master of Sciencein Economics. Haramaya University.

Akanbi, A; Raheem, A. \& Bolatito, I.(2011).Technical efficiency of maize production in Ogun State, Nigeria,Journal of Development and Agricultural Economics, Federal University of Agriculture Abeokuta, Nigeria. 7(2): pp.55-60,

Beyan Ahmed, Jema Haji and Endrias Geta, 2013. Analysis of farm households' technical efficiency in production of smallholder farmers: the case of Girawa District, Ethiopia. Journal of Agriculture and Environmental Science, 13(12): 1615-1621.

Coelli, T., D.S. P. Rao and C.J.O.Donell G.E. Battese (2005). Introduction to Efficiency and Production Analysis, USA. Springer.

CSA, Report of Federal Democratic Republic of Ethiopia, 2016. Statistical Report on Socio-Economic Characteristics of the Population in Agricultural Households, Land Use Area and Production of Crops. Addis Ababa: CSA: pp.193-211.

Dawit Alemu,S. Rashid., and R. Tripp (2010). Seed system potential in Ethiopia Constraints and Opportunities forenhancing the seed sector. IFPRI, Washington DC.

DARDO (District Agriculture and Rural Development Office) 2018/19. Progressreportand information posted on office (Unpublished)

FAO, 2014. Analysis of price incentives for maize in Ethiopia for the time period 2005-2013. 
FAO. (2011). The State of Food and Agriculture (2010-11). Women in Agriculture: Closing the Gender Gap for Development. Rome.

Geta, E., Bogale, A., Kassa, B. and Eyasu, E. (2013). Productivity and Efficiency Analysis ofSmallholder Maize Producers in Southern Ethiopia. Journal of Hum. Ecol 41(1): pp 67-75.

Isaac, O., 2011. Technical efficiency of maize production in Oyo state. Department ofAgricultural Economics and Extension, University of Technology,P.M.B 4000Ogbomoso.

Jema Haji. 2008. Economic Efficiency and Marketing Performance of Vegetable Production the Eastern and Central Parts of Ethiopia. Doctoral Dissertation, Swedish University of Agricultural Science, Uppsala, Sweden.

Kareem, R.,O. Dipeolu, A.B. Aromolaran., \& A. Samson.(2008).Analysis of Technical,Allocative and Economic Efficiency of Different Pond Systems in Ogun State, Nigeria. African Journal of Agricultural Research, Vol. 3, no, 4 pp. $246-25$

MoA (Ministry of Agriculture). (2015). Animal and Plant Health Regulatory Directorate. Crop variety register, Issue No. 15. Addis Ababa, Ethiopia.

MoFED (Ministry of Finance and Economic Development). 2015. Growth and Transformation Plan 2010/112014/15. Addis Ababa, Ethiopia.

Rashid.S., Kindie Getnet, and Solomon Lemma (2010). Maize Value Chain Potential in Ethiopia, Constraints and opportunities for enhancing the system. IFPRI (International Food Policy Research Institute), USA.

Sisay, D.,Jema, H.,Degye ,G .\& Abdi-Khalil, E.(2015). Technical, allocative, and economic efficiency among smallholder maize farmers in Southwestern Ethiopia: Journal of Development and Agricultural Economics, Vol.7 (8): pp. 283-292.

Solomon Bizuayehu (2014). Technical efficiency of major crops in Ethiopia. M.Sc Thesis.University of Oslo.

UNDP (United Nations Development Program). 2017. National Human Development Report 2016 Ethiopia,Accelerating Inclusive Growth for Sustainable Human Development in Ethiopia, Addis Ababa, Ethiopia

Yamane, T. I. (1967). Statistics: An Introductory Analysis Second Edition. New York, Harper and row. 